\title{
Validation Study of the Mini-Mental State Examination in Urdu Language for Pakistani Population
}

\author{
Safia Awan ${ }^{1}$, Naila Shahbaz ${ }^{2}$, Syed Wasim Akhtar ${ }^{3}$, Arsalan Ahmad $^{4}$, Sadaf Iqbal ${ }^{5}$, Sellal Ahmed ${ }^{6}$, \\ Haider Naqvi ${ }^{7}$ and Mohammad Wasay ${ }^{8, *}$ \\ ${ }^{1}$ Department of Medicine, ${ }^{8}$ Neurology, ${ }^{7}$ Psychiatry, Aga Khan University, Karachi \\ ${ }^{2}$ Department of Neurology, Dow University of Health Sciences, Karachi \\ ${ }^{3}$ Neurology Section, Department of Medicine, Karachi Medical \& Dental College and Abbasi Shaheed Hospital, \\ Karachi \\ ${ }^{4}$ Department of Neurology, Shifa International Medical College and Hospital, Islamabad \\ ${ }^{5}$ Department of Neurology and ${ }^{6}$ Geriatrics, Liaquat National Hospital, Karachi
}

\begin{abstract}
Validation study of the Mini-Mental State Examination in Urdu language for Pakistani population
Objective: This study was conducted primarily to validate and determine the optimal cutoff score in the diagnosis of dementia among Pakistani's and study the effects of gender and education on the MMSE performance in our population.

Methods: Four hundred participants took part in the study. Patient with dementia recruited from five major hospitals from Pakistan. The MMSE was translated into Urdu.

Results: There were 61 men and 39 women in dementia group and 225 men and 75 women in the control group. The mean score of Urdu MMSE were lower in patients with dementia $18.5 \pm 5.6$ (range 0-30) as compared to the controls $26.8 \pm 2.6$ (range 7-30). This difference between groups was statistically significant $(\mathrm{p}<0.001)$. Educational based MMSE score below 15 yielded perfect sensitivity and specificity for the diagnosis of dementia.

Conclusions: These finding confirm the influence of level of education on MMSE score and education stratified cutoff scores should be used while screening for cognitive impairment in this population.
\end{abstract}

Keywords: Mini mental status examination, cognitive function, dementia, mental disorders, validation tool.

\section{INTRODUCTION}

Overall burden of Neurological diseases in the world is around $6.5 \%$. It ranges from $4-5 \%$ in lower income countries as compared to $10-11 \%$ in high income countries [1]. Overall death and disability related to neurological diseases is higher than HIV/AIDS, neoplasms, Ischemic heart diseases and Tuberculosis. More than half of the disability due to neurological diseases is related to stroke followed by Dementia, Migraine, Epilepsy and tetanus [1].

Dementia in general and Alzheimer's disease (AD) in particular, affect elderly people all around the world. In epidemiological studies of dementia and Alzheimer's disease (AD) in developed countries, the prevalence rates of dementia for persons aged 65 years and older have been estimated between $1.3 \%$ and $6.2 \%$ [2]. According to the

*Address correspondence to this author at the Department of Neurology, Aga Khan University, Stadium Road, Karachi 74800, Pakistan;

Tel: 9221 4930051(office), 92333 2234688(mobile);

E-mail: mohammad.wasay@aku.edu
Global Burden of Disease estimates for the 2003 World Health Report [3], dementia contributed $11.2 \%$ of years lived with disability in people aged 60 years and older; more than stroke, musculoskeletal disorders, cardiovascular disease, and all forms of cancer.

Dementia is largely a clinical diagnosis and a clinical test (MMSE- mini mental status examination) is available with high specificity and sensitivity to diagnose this condition. The Mini-Mental State Examination (MMSE) [4] is a reliable screening test for cognitive impairment with older and hospitalized adults. This scale has been used as a brief cognitive tool which allows serial assessment and monitoring of the cognitive function of patients including orientation, memory, language, attention, calculation and ability to follow simple verbal and written commands with dementia over time. Despite criticism that it relies on verbal response and reading and writing, it still remains one of the widely utilized clinical screening tools in the diagnosis of dementia.

This test is devised in English, the maximum score is 30, and a cutoff score 24 has been reported as a normal range for 
cognition and has a sensitivity of $84 \%$ and a specificity of $80 \%$ in detecting dementia across different age groups [4]. However, validation studies in other non English speaking countries have reported different sensitivities and specificities [2, 5-9]. These differences are not due to variation in the native language but result of cultural and ethnic [10] differences has been shown to modify performance in the test [10]. Furthermore, the education levels [11] may also affect the results of MMSE within a specific community, hence the need for each country to have its own validation study to determine the optimal cutoff scores in the diagnosis of dementia.

With 180.1 million residents reported in 2012, Pakistan is the sixth most populated country in the world More than sixty languages are spoken in Pakistan, including a number of provincial languages. Urdu is the national language of Pakistanis and Urdu is also one of the officially recognized languages in India. This test has not been validated in Urdu language. This is a major limitation in conducting population based studies for dementia. This test is being used in Pakistan by neurologist, psychiatrists, psychologist and other physician but due to lack of validation studies physicians are using cutoff values for US, UK and other developed countries which may be misleading for our patient population. Therefore, this study was conducted primarily to validate and determine the optimal cutoff score in the diagnosis of dementia among Pakistani's and secondarily to study the effects of gender and education on the MMSE performance in our population.

\section{MATERIALS AND METHODOLOGY}

This is a matched case control study involved patients with dementia from the urban hospitals. Patient with dementia recruited from five major hospitals from Pakistan. The controls were age matched normal individuals from urban communities and those attending the hospital for reason other than dementia between january 2013 to july 2013. Patients attending neurology and dementia outpatient clinics were interviewed by neurologist or psychiatrists and those who fulfilled the Diagnostic and Statistical manual of Mental Disorders IV criteria for dementia [12] were invited to participate. Prior informed consent was obtained from all participants. The patients were excluded if they were neurological disorders, blindness, deafness and other mental disabilities.

\section{INSTRUMENT}

This is an 11-item instrument, obtained by forward and back translation of Folstein's MMSE, by researchers who were fluent in both the English and Urdu languages. The researchers administering the MMSE were blinded to the original clinical diagnosis given. In case of illiterate subjects, the following two items were modified: instead of reading a command it was communicated verbally and subjects were asked to perform the command ('close your eyes'); instead of asking participants to write a spontaneous sentence, subjects were asked to articulate a spontaneous sentence.
Convenience sampling was used by getting the questionnaires filled during the study period.

The study was approved by the Ethical Review Committee (ERC) of the Aga Khan University, Hospital. A trained MBBS qualified doctor administered the study questionnaire and the MMSE.

\section{STATISTICAL ANALYSIS}

Descriptive analysis was done for demographic and clinical features and results were presented as mean \pm standard deviation for quantitative variables and number (Percentage) for qualitative variables. Comparison between groups and educational backgrounds was performed with the ANOVA. The mean of Urdu MMSE score were compared between genders in all subjects by using independent samples t-test. The internal consistency of MMSE was assessed by Cronbach's $\alpha$ for the total scale and each individual item. In order to determine the optima cutoff scores, the sensitivity and specificity were calculated. All analyses were performed with the SPSS software package, version 19.0 (SPSS, Chicago, Ill.,USA). All p-values were two sided and considered as statistically significant if $<0.05$.

\section{RESULTS}

A total of four hundred participate in this study. On hundred participant $(25 \%)$ had a clinical diagnosis of dementia based on criteria of the Diagnostic and Statistical Manual of Mental Disorders IV [12] and 300 (75\%) were controls. There were 61 men and 39 women in dementia group and 225 men and 75 women in the control group. Forty two (10.5\%) subjects were illiterate; $28 \%$ of the samples were received school level education (up to 10 grades). The mean score of Urdu MMSE was $24.8 \pm 5.7$ (range; 0-30); the mean scores for MMSE were lower in patients with dementia $18.5 \pm 5.6$ (range 0-30) as compared to the controls $26.8 \pm 2.6$ (range 7-30) Table 1 . This difference between groups was statistically significant $(\mathrm{p}<0.001)$. The mean MMSE score was $25.3 \pm 4.8$ for male and $23.5 \pm 7.3$ for female ( $p$ value $=0.004$ ).

The subjects with primary education and no education had significantly lower mean score in both group. Subjects with illiterate and up to 10 grades had significantly lower mean scores in patients with dementia group compare to those with higher education $(\mathrm{p}<0.001)$. In control group, illiterate group had lower mean MMSE as compared to secondary education group. The mean MMSE score were high in male as compared to female in both groups but this difference was not statistically significant (Table $\mathbf{2}$ ).

These results were further stratified by gender. The mean MMSE scores were significantly better in males with higher education compared to those with primary or no education in dementia group and control group. Significant gender difference present in male subjects with lower education in both groups. Having secondary or higher education did not significantly affect the MMSE score in females (Table 3). 
Table 1. Demographic characteristics of study population $(n=400)$.

\begin{tabular}{|c|c|c|c|c|}
\hline & Total & $\operatorname{Dementia}(n=100)$ & No dementia $(n=300)$ & p value \\
\hline Age, in years & $64.4 \pm 18.0$ & $66.7 \pm 11.2$ & $61.02 \pm 10.3$ & \\
\hline Male & $286(71.5)$ & $61(61)$ & $225(75)$ & 0.01 \\
\hline \multicolumn{5}{|l|}{ Education } \\
\hline Illiterate & $42(10.5)$ & $24(24)$ & $18(6.0)$ & $<0.001$ \\
\hline Primary (1-5 grade) & $38(9.5)$ & $14(14)$ & $24(8.0)$ & \\
\hline MMSE-Urdu score & $24.8 \pm 5.7$ & $18.5 \pm 7.6$ & $26.8 \pm 2.6$ & $<0.001$ \\
\hline & & & & \\
\hline
\end{tabular}

Table 2. Mean MMSE-Urdu score based on educational level and gender.

\begin{tabular}{|c|c|c|c|}
\hline \multicolumn{4}{|l|}{ Patients with dementia } \\
\hline Education & $14.3 \pm 7.6$ & $<0.001$ & \\
\hline Illiterate (1) & $17.2 \pm 6.3$ & & (1) vs. (5) $<0.001$ \\
\hline Matric (6-10 grades) 3 & $20.3 \pm 1.1$ & & (3) vs (5) 0.006 \\
\hline Up to graduation (4) & $25.4 \pm 4.7$ & & (4) vs (1) 0.03 \\
\hline \multicolumn{4}{|l|}{ Master (5) } \\
\hline Male & $19.7 \pm 6.5$ & 0.05 & \\
\hline Female & $16.7 \pm 8.8$ & & \\
\hline Patient without dementia & & & \\
\hline
\end{tabular}


Table 2. contd...

\begin{tabular}{|c|c|c|c|}
\hline & Mean Score \pm SD & p Value & Pairwise Comparison \\
\hline \multicolumn{4}{|l|}{ Education } \\
\hline Illiterate & $25.0 \pm 5.4$ & 0.01 & (1) vs (3) 0.02 \\
\hline Primary ( $1-5$ grade) & $26.3 \pm 2.8$ & & \\
\hline Matric (6-10 grades) & $27.2 \pm 2.7$ & & \\
\hline Up to graduation & $27.1 \pm 2.0$ & & (4) vs (1) 0.01 \\
\hline Master & $26.7 \pm 2.2$ & & \\
\hline \multicolumn{4}{|l|}{ Gender } \\
\hline Male & $26.8 \pm 2.7$ & 0.53 & \\
\hline Female & $27.0 \pm 2.0$ & & \\
\hline
\end{tabular}

Table 3. Mean MMSE-Urdu score inpatients with and without dementia between genders, based on educational level.

\begin{tabular}{|c|c|c|c|c|}
\hline & Male & P Value & Female & p value \\
\hline \multicolumn{5}{|l|}{ Dementia group } \\
\hline \multicolumn{5}{|l|}{ Education } \\
\hline Illiterate & $16.8 \pm 5.4$ & 0.001 & $11.9 \pm 8.8$ & 0.12 \\
\hline Primary (1-5 grade) & $16.3 \pm 6.4$ & & $18.3 \pm 6.5$ & \\
\hline Matric (6-10 grades) & $17.8 \pm 6.7$ & & $16.8 \pm 9.8$ & \\
\hline Up to graduation & $20.4 \pm 5.8$ & & $20.2 \pm 6.0$ & \\
\hline Master & $26.5 \pm 3.9$ & & $23.2 \pm 5.9$ & \\
\hline \multicolumn{5}{|l|}{ Patient without dementia } \\
\hline \multicolumn{5}{|l|}{ Education } \\
\hline Illiterate & $24.8 \pm 5.5$ & 0.01 & 29 & 0.8 \\
\hline Primary (1-5 grade) & $26.2 \pm 2.9$ & & $27.5 \pm 0.7$ & \\
\hline Matric (6-10 grades) & $27.2 \pm 2.8$ & & $28 \pm 2.6$ & \\
\hline Up to graduation & $27.1 \pm 2.0$ & & $26.9 \pm 2.0$ & \\
\hline Master & $26.5 \pm 2.2$ & & $27 \pm 2.2$ & \\
\hline
\end{tabular}


Table 4. Screening ability of MMSE-Urdu score based on education level.

\begin{tabular}{|c|c|c|c|c|c|c|}
\hline Cutoff Score & Combine & Illiterate & Primary (1-5 grade) & Matric (6-10 Grades) & Up to Graduation & Master \\
\hline Optimal cutoff & 24 & 10 & 10 & 12 & 12 & 15 \\
\hline Specificity (\%) & 93 & 94 & 100 & 100 & 100 & 100 \\
\hline
\end{tabular}

The sensitivity and specificity for optimal cutoff score of Urdu MMSE are shown in Table 4. The cutoff score of 24 appeared to be the best with sensitivity of $69 \%$ and specificity of $93 \%$. Educational based MMSE score showed different cutoff values. Any score below 15 yielded perfect sensitivity and specificity for the diagnosis of dementia in this study. The internal consistency coefficient was obtained. Overall, the Cronbach's $\infty$ was 0.74 for Urdu MMSE.

\section{DISCUSSION}

The MMSE has been one of the most widely used instruments for screening dementia. It is also used to estimate the severity of cognitive impairment and to follow the course of cognitive changes in an individual over time. This study showed that Urdu version of MMSE is a valid and reliable measure in the diagnosis of dementia in our population. The Urdu MMSE score was found it to be a user friendly, easy to administer scale.

Screening tests should be able to detect cognitive impairment and discriminate between subjects with and without disease. Results showed that the mean difference of total scores between groups was significant. This signifies the ability of the instrument to discriminate between subjects with normal and abnormal cognitive function.

The mean MMSE score for control group in this study is high and this finding is consistent with the previous studies $[13,14]$. The reason may be that most of control subjects in this study were educated as compare to dementia group. $\mathrm{Xu}$ et al. calculated different cutoff score for educated and uneducated individuals [15].

This study showed that the educational level, similar to previous results, significantly affect the MMSE score [11, $13,15,16]$. The mean MMSE scores improved progressively with improvement in the education level from primary to higher levels in dementia group. In males, mean score increased significantly as education level increased in both groups. Though, in females' education level did not affect the MMSE performance in dementia and control groups. However, study from Malaysia indicate that educational background affects the mean MMSE score in control group [13]. Therefore, a variety of cutoff scores could be found in the literature. The cutoff scores are generally higher for education individuals than those who are uneducated [13, 15]. The greater performance of the educated subjects as compared to the uneducated subjects confirmed the educational bias of the MMSE, as other studies have reported [17-20]. The mean score of above primary education level subjects falls within the conventional cut-off score of $<24$ in Western countries [4], and there would have been no need for any adjustment if all the individuals were literate.

Male performance is significantly better in MMSE score compared to female. Male have a high MMSE score as compared to female in dementia group. Gender has been known to influence MMSE score [21, 22]. A study using Arabic MMSE version showed lower MMSE score for women [19]. However, a study from Persia reported that gender had no effect on MMSE score [14]. Significant sociodemographic factors and gender differences in MMSE score among cases with low educational background have been reported previously $[11,13,18,23]$.

The optimal cutoff scores 23/24 has a low sensitivity of $69 \%$ with specificity of $93 \%$. Studies in other population groups have also yielding different cutoff scores. A study from South Korea showed the similar cutoff but high sensitivity $92 \%$ with $91.5 \%$ specificity [24]. The sensitivity of the Persian MMSE was $98 \%$ with a score of 23 [14]. While in Saudi Arabia population, a cutoff score of 11 was $100 \%$ sensitive and $97 \%$ specific for the diagnosis of dementia [19]. These observations further highlight the need for each population to use their own validated versions of the MMSE. Based on Cronbach's $\infty$ all items of MMSE had a discriminatory values in differentiating those with and without dementia, the $\infty$ coefficient was 0.74 , implies that this instrument is valid and reliable as a screening tool for dementia in our population

\section{CONCLUSION}

In conclusion, this is the first validation study of the MMSE-Urdu among Pakistani population. The cutoff score presented here should be considered with caution. Pakistan is a developing country with limited health care resources and a literacy rate of only $45 \%$. Prior to screening, the patient's education level should be ascertained. Hence, the results might not generalize to all healthy subjects and to patients with mild cognitive impairment. A future population based study with large sample of subject has been design to investigate the reliability of instrument in Urdu speaking communities. 


\section{FUNDING}

This work was supported by an unrestricted grant from Neurology awareness and research foundation (NARF) and Lundebeck, Pakistan.

\section{CONFLICT OF INTEREST}

The authors confirm that this article content has no conflict of interest.

\section{ACKNOWLEDGEMENTS}

We acknowledge Hakeem Jokhio MPH, PhD (Peoples Medical University, Nawab Shah) for support in proposal development and Khalid Mir Khan (Research officer, Aga Khan University) for data collection.

\section{REFERENCES}

[1] World Health Organization G, Switzerland. Neurological disorders: public health challenges. World Health Organization 2006.

[2] Vas CJ, Pinto C, Panikker D, et al. Prevalence of dementia in an urban Indian population. Int Psychoger 2001; 13(4): 439-50.

[3] Walt G. WHO's World Health Report 2003: Shaping the future depends on strengthening health systems. BMJ 2004; 328(7430): 6.

[4] Folstein MF, Folstein SE, McHugh PR. Mini-mental state $\odot:$ a practical method for grading the cognitive state of patients for the clinician. J Psyc Res 1975; 12(3): 189-98.

[5] Fountoulakis KN, Tsolaki M, Chantzi H, Kazis A. Mini mental state examination (MMSE): a validation study in Greece. American J Alzheimer's Dis Dement 2000; 15(6): 342-5.

[6] Prince M, Acosta D, Chiu H, Scazufca M, Varghese M. Dementia diagnosis in developing countries: a cross-cultural validation study. Lancet 2003; 361(9361): 909-17.

[7] Beaman SRd, Beaman PE, Garcia-Pena C, et al. Validation of a modified version of the Mini-Mental State Examination (MMSE) in Spanish. Aging Neuropsychol Cogn 2004; 11(1): 1-11.

[8] Kathriarachchi ST, Sivayogan S, Jayaratna SD, Dharmasena SR. Comparison of three instruments used in the assessment of dementia in Sri Lanka. Ind J Psychiat 2005; 47(2): 109.

[9] Lee J-Y, Lee DW, Cho S-J, et al. Brief screening for mild cognitive impairment in elderly outpatient clinic: validation of the Korean version of the Montreal Cognitive Assessment. J Geriat Psychiat Neurol 2008; 21(2):104-10.

[10] Espino DV, Lichtenstein MJ, Palmer RF, Hazuda HP. Ethnic differences in miniâ€(?) mental state examination (mmse) scores: where you live makes a difference. J Am Geriat Soc 2001; 49(5): $538-48$.
[11] de Ỹ̃@benes M, Otero A, Zunzunegui MaV, RodrÃ-guezâ€ $९$ Laso A, SÃ $;$ nchezâ€ $@ S \tilde{A}_{i}$ nchez F, Del ST. Validation of a short cognitive tool for the screening of dementia in elderly people with low educational level. Int J Geriat Psychiat 2003; 18(10): 925-36.

[12] American Psychiatric A. Diagnostic and statistical manual of mental disorders: DSM-IV-TRÂ®. American Psychiatric Pub 2000.

[13] De Silva R, Disanayaka S, De Zoysa N, et al. Norms for the minimental state examination from a sample of Sri Lankan older people. Int J Geriat Psychiat 2009; 24(7): 666-70.

[14] Ansari NN, Naghdi S, Hasson S, Valizadeh L, Jalaie S. Validation of a Mini-Mental State Examination (MMSE) for the Persian population: a pilot study. App Neuropsychol 2010; 17(3): 190-5.

[15] Xu G, Meyer JS, Huang Y, Du F, Chowdhury M, Quach M. Adapting Mini-Mental State Examination for dementia screening among illiterate or minimally educated elderly Chinese. Int $\mathbf{J}$ Geriat Psychiat 2003; 18(7): 609-16.

[16] Rosselli Mn, Tappen R, Williams C, Salvatierra J. The relation of education and gender on the attention items of the Mini-Mental State Examination in Spanish speaking Hispanic elders. Arch Clin Neuropsychol 2006; 21(7): 677-86.

[17] Katzman R, Zhang M, Wang Z, et al. A Chinese version of the Mini-Mental State Examination; impact of illiteracy in a Shanghai dementia survey. J Clin Epidemiol 1988; 41(10): 971-8.

[18] Mungas D, Marshall SC, Weldon M, Haan M, Reed BR. Age and education correction of Mini-Mental State Examination for English-and Spanish-speaking elderly. Neurology 1996; 46(3): 700-6.

[19] Al-Rajeh S, Ogunniyi A, Awada A, Daif A, Zaidan R. Preliminary assessment of an Arabic version of the Mini-Mental state examination. Ann Saudi Med 1999; 19(2): 150-2.

[20] Boban M, Maloj $\ddot{\mathrm{A}} \oplus \mathrm{i} \ddot{\mathrm{A}} \ddagger \mathrm{B}$, Mimica N, et al. The reliability and validity of the Mini-Mental State Examination in the elderly Croatian population. Dement Geriatr Cogn Disord 2012; 33(6): 385-92.

[21] Grigoletto F, ZappalÃ G, Anderson DW, Lebowitz BD. Norms for the Mini-Mental State Examination in a healthy population. Neurology 1999; 53(2): 315.

[22] Wind AW, Schellevis FOG, Van Staveren G, Scholten RJ, Jonker C, Van Eijk JTM. Limitations of the Mini-Mental State Examination in diagnosing dementia in general practice. Int $\mathrm{J}$ Geriat Psychiat 1997; 12(1): 101-8.

[23] Brijnath B. Use of the MMSE to screen for dementia in Delhi. Dementia 2011; 10(4): 625-35.

[24] Park JH, Kwon YC. Modification of the mini-mental state examination for use in the elderly in a non-western society. Part 1 . Development of Korean version of mini-mental state examination. Int J Geriatr Psychiat 1990; 5(6): 381-7. 